Paper:

\title{
Preliminary Analysis for Evaluation of Local Site Effects in Lima City, Peru from Ground Motion Data by Using the Spectral Inversion Method
}

\author{
Selene Quispe*, Hiroaki Yamanaka*, Zenon Aguilar**, \\ Fernando Lazares ${ }^{* *}$, and Hernando Tavera*** \\ * Department of Environmental Science and Technology, Tokyo Institute of Technology \\ 4259 Nagatsuta, Midori-ku, Yokohama, Kanagawa 226-8502, Japan \\ E-mail: selene.q.aa@m.titech.ac.jp, yamanaka@depe.titech.ac.jp \\ ** Japan Peru Center for Earthquake Engineering and Disaster Mitigation (CISMID), \\ Faculty of Civil Engineering, National University of Engineering \\ Av. Túpac Amaru $N^{\circ}$ 1150, Lima 25, Peru \\ *** Geophysical Institute of Peru (IGP) \\ Calle Badajoz \# 169, Mayorazgo IV Etapa, Ate Vitarte, Lima, Peru \\ [Received November 26, 2012; accepted December 13, 2012]
}

Effects of local site, propagation path and source in ground motion records observed in Lima, Peru, were separated by the spectral inversion method proposed by Iwata and Irikura (1986 [1], 1988 [2]) to examine the relation between local subsurface conditions and local site amplifications in a frequency range from 0.5 to $20 \mathrm{~Hz}$. S-wave portions of accelerograms in horizontal components observed at 5 stations for 11 events along the Pacific coast of Lima city, Peru, were analyzed. The $\mathbf{Q}$ factor was obtained from our inversion results as frequency-dependent function $Q_{S}(f)=$ $80.4 f^{0.63}$. In terms of local site effects, stations located on alluvial gravel deposits were likely to suffer amplification at frequencies larger than $4 \mathrm{~Hz}$, while one station (CAL site) located on soft soil sediment has different behavior of amplification. We also compared our results with 1-D theoretical computation, observed standard spectral ratio and observed $\mathrm{H} / \mathrm{V}$ spectra in previous studies, finding that site responses determined by different methods are similar. In addition, we analyzed the relationship between average $S$-wave velocity in the top 10 meters and the average site amplification factor in a frequency range between $0.5 \mathrm{~Hz}$ and $10.0 \mathrm{~Hz}$, showing a good correlation between the two parameters. We also calculated the average transfer function $(A v T F)$ to compare it with the existing amplification map for Lima city, and found that our calculations differed from this map.

Keywords: Lima City, La Molina, Callao, site amplification factor, spectral inversion method

\section{Introduction}

In the last 60 years, Lima city, Peru, has been hit by earthquakes with the biggest $\mathrm{Mw}$ of 8.1, according to the earthquake catalog compiled by the Geophysical Institute of Peru (IGP). Previous studies [3,4] indicated that most of these events have caused unusually low level of damage in the city itself compared with other places of the world hit by earthquakes with similar magnitudes. The explanation of this is that a big portion of Lima city is underlain by sandy, boulder gravel, poorly graded, but usually very dense, with rounded cobbles and boulders up to $50 \mathrm{~cm}$ in diameter, which is locally named as Lima Conglomerate or Cascajo. This Quaternary alluvial deposit has a thickness of at least $86 \mathrm{~m}[5,6]$. It was during an earthquake in October 3, 1974, $(\mathrm{Mw}=8.1)$ with a focal depth about $13 \mathrm{~km}$ that a few areas outside of the center of Lima were severely damaged, such as La Campiña (Chorrillos), La Molina and Callao - La Punta [5]. After that, several investigations have been carried out for the purpose of finding out the reasons and evaluating local site effects at Lima city [5,7-9]. These works have proven that the previously mentioned places suffer from large amplifications in the long period range.

The present study uses ground motion records observed along the Pacific coast of Lima city, Peru, for the assessment of local site amplification. The relation between local subsurface conditions and the local site effect in some areas of Lima city are discussed based on results obtained using the spectral inversion method.

\section{Motion Data and Accelerometer Stations}

Earthquake records from 2005 to 2008 were used in this study to analyze site effects at 5 stations in Lima city. Table 1 details the 11 events used in this work, and Fig. 1 shows locations of recording sites. These seismic events are shallow and intermediate earthquakes (depth $<$ $140 \mathrm{~km}$ ), from $50 \mathrm{~km}$ to $180 \mathrm{~km}$ in hypocentral distance, i.e., the distance from each seismic recording station to the earthquake's epicenter, as shown in Fig. 2. The Local Magnitude $\left(\mathrm{M}_{\mathrm{L}}\right)$ of seismic events ranges from 4.0 to 
Table 1. Event information.

\begin{tabular}{|ccccccccccc|}
\hline $\begin{array}{c}\text { Date } \\
\text { yyyy/mm/dd }\end{array}$ & $\begin{array}{c}\text { Hour:min } \\
\text { hr:meg }\end{array}$ & $\begin{array}{c}\text { Lat. } \\
(\mathrm{deg})\end{array}$ & $\begin{array}{c}\text { Mag. } \\
(\mathrm{ML})\end{array}$ & $\begin{array}{c}\text { Depth } \\
(\mathrm{km})\end{array}$ & $\begin{array}{c}\text { Site } \\
\text { CSM }\end{array}$ & $\begin{array}{c}\text { Site } \\
\text { CAL }\end{array}$ & $\begin{array}{c}\text { Site } \\
\text { MOL }\end{array}$ & $\begin{array}{c}\text { Site } \\
\text { CDLCIP }\end{array}$ & $\begin{array}{c}\text { Site } \\
\text { LMO }\end{array}$ \\
\hline $2005 / 03 / 02$ & $13: 48$ & -76.14 & -11.86 & 5.7 & 124 & $*$ & $*$ & $*$ & - & - \\
$2005 / 07 / 19$ & $8: 45$ & -77.11 & -12.59 & 4.1 & 48 & $*$ & - & $*$ & - & - \\
$2005 / 07 / 25$ & $6: 51$ & -77.33 & -12.24 & 4.0 & 42 & $*$ & - & $*$ & - & - \\
$2005 / 10 / 14$ & $5: 01$ & -76.74 & -12.40 & 4.4 & 74 & $*$ & $*$ & $*$ & - & - \\
$2005 / 11 / 10$ & $16: 38$ & -76.22 & -12.26 & 4.0 & 71 & $*$ & $*$ & $*$ & - & - \\
$2005 / 12 / 27$ & $17: 02$ & -76.57 & -12.22 & 4.5 & 99 & $*$ & - & $*$ & - & - \\
$2006 / 05 / 26$ & $1: 57$ & -77.41 & -11.74 & 4.5 & 38 & $*$ & - & $*$ & - & $*$ \\
$2006 / 12 / 11$ & $21: 53$ & -77.37 & -11.64 & 4.2 & 54 & - & - & $*$ & - & $*$ \\
$2008 / 03 / 29$ & $6: 40$ & -77.73 & -12.17 & 4.3 & 48 & $*$ & $*$ & - & $*$ & - \\
$2008 / 03 / 29$ & $12: 51$ & -77.25 & -12.25 & 5.3 & 51 & $*$ & $*$ & - & $*$ & $*$ \\
$2008 / 06 / 07$ & $13: 06$ & -77.29 & -12.48 & 5.0 & 67 & $*$ & $*$ & - & - & $*$ \\
\hline
\end{tabular}

Source parameters were determined by the Geophysical Institute of Peru (IGP)

$(*$ means that the event was recorded)

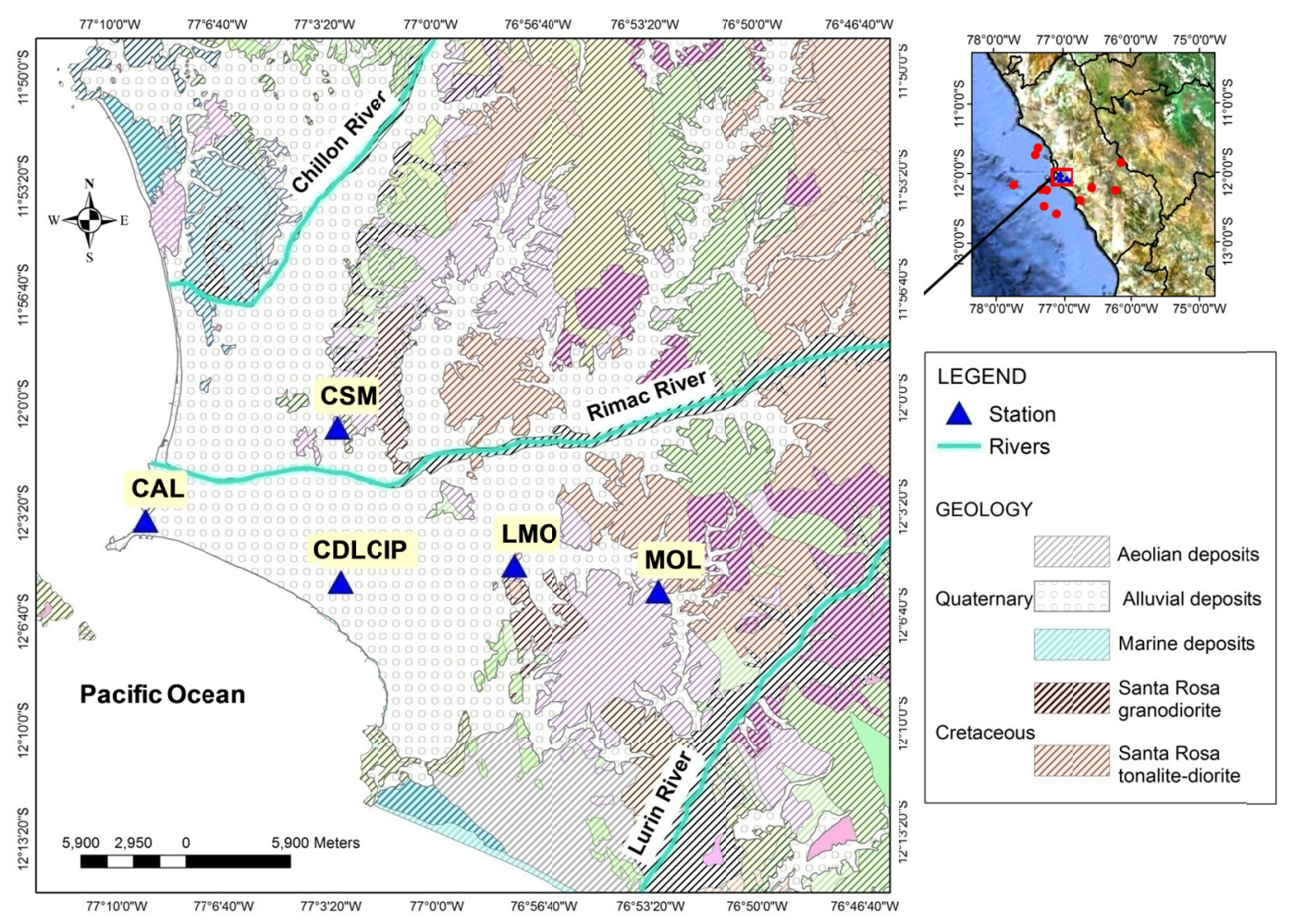

Fig. 1. Location of stations and epicenters on geological map. Red circles show epicenters of events used in this work. Blue triangles represent stations located on the geological map of Lima city [10].

5.7. Because PGAs were mostly as small as $120 \mathrm{~cm} / \mathrm{s}^{2}$, we assume that soil had a linear site response.

Four stations - CSM, CAL, MOL and CDLCIP - are maintained by the Japan Peru Center for Earthquake Engineering and Disaster Mitigation (CISMID) Accelerometer Network, and one station, LMO, is deployed by the Geophysical Institute of Peru (IGP). Locations of all observation sites are shown in Fig. 1 on a geological map of Lima city [10]. According to this map, most of the stations - sites CSM, CAL, MOL and CDLCIP - are basically located on alluvial soil deposits belonging to the Holocene (Fig. 1), while site LMO is located on Creta-

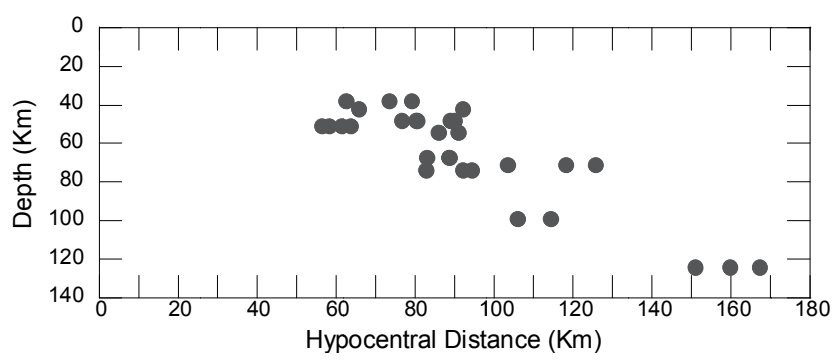

Fig. 2. Distribution of hypocentral distance and depth. 
Table 2. Stations, locations and surface geology.

\begin{tabular}{|ccccccc|}
\hline Site ID & District & $\begin{array}{c}\text { Long. } \\
(\mathrm{deg})\end{array}$ & $\begin{array}{c}\text { Lat. } \\
(\mathrm{deg})\end{array}$ & $\begin{array}{c}\text { Geological } \\
\text { Age }\end{array}$ & Geology & $\begin{array}{c}\text { Local Surface } \\
\text { conditions }\end{array}$ \\
\hline CSM & Rimac & -77.050 & -12.010 & Quaternary & Alluvial & Alluvial gravel \\
CAL & Callao & -77.150 & -12.060 & Quaternary & Alluvial & Clays and gravels \\
MOL & La Molina & -76.890 & -12.100 & Quaternary & Alluvial & Alluvial gravel \\
CDLCIP & San Isidro & -77.050 & -77.050 & Quaternary & $\begin{array}{c}\text { Alluvial } \\
\text { Alluvial gravel }\end{array}$ \\
LMO & La Molina & -76.950 & -12.080 & Cretaceous & $\begin{array}{c}\text { Santa Rosa } \\
\text { Granodiorite }\end{array}$ & Rock \\
\hline
\end{tabular}

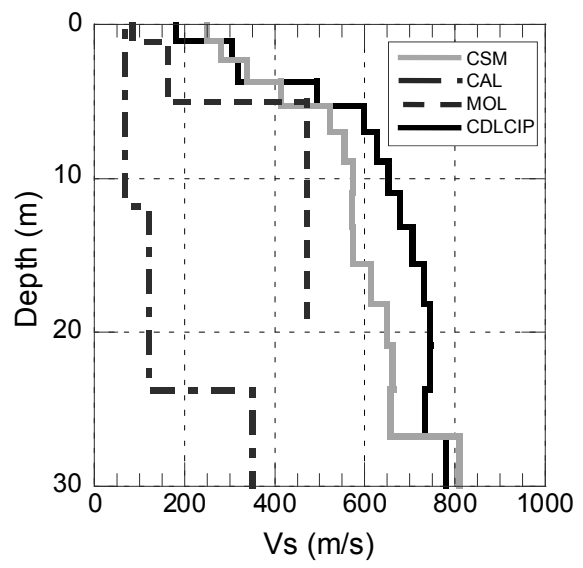

Fig. 3. Shear wave velocity profiles for stations used in this study.

ceous intrusive rock (Fig. 1). Exact coordinates, geological age, geology and local surface conditions of each site are shown in Table 2.

$\mathrm{S}$-wave velocity profiles are available for most of the sites (Fig. 3). S-wave velocity profiles at CSM and CDLCIP were determined by the Multichannel Analysis of Surface Wave (MASW) technique (Piedra R., personal communication). $V_{S}$ profiles for CAL and MOL sites were estimated by the inversion of spectral ratios $(\mathrm{H} / \mathrm{V}$ and standard techniques) [11], not obtained through geophysical methods.

\section{Method of Analysis}

At the start of this investigation, we analyze available data using the Spectral Inversion Method (SIM) $[1,2]$ since from a practical point of view, this method offers the advantage that records from some events can be included in inversion even if these events are not recorded at all sites. This offers the advantage of more complete exploitation of the data set [12].

The inversion method separates source, path, and site effects simultaneously from observed S-wave Fourier amplitude spectra by taking the logarithm of the following equation

$$
O_{i j}(f)=S_{i}(f) \cdot R_{i j}^{-1} \cdot \exp \left(-\pi R_{i j} f / Q_{S}(f) V_{S}\right) \cdot G_{j}(f)
$$

where $O_{i j}(f)$ is the observed S-wave Fourier amplitude spectrum of the $i^{\text {th }}$ event at the $j^{\text {th }}$ station, $S_{i}(f)$ the source amplitude spectrum of the $i^{\text {th }}$ event, $G_{j}(f)$ the site

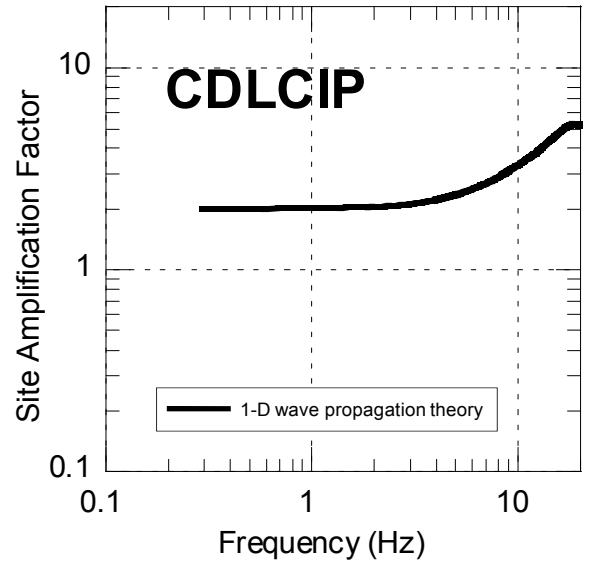

Fig. 4. Theoretical amplification factor for reference site CLDCIP used as a constraint condition.
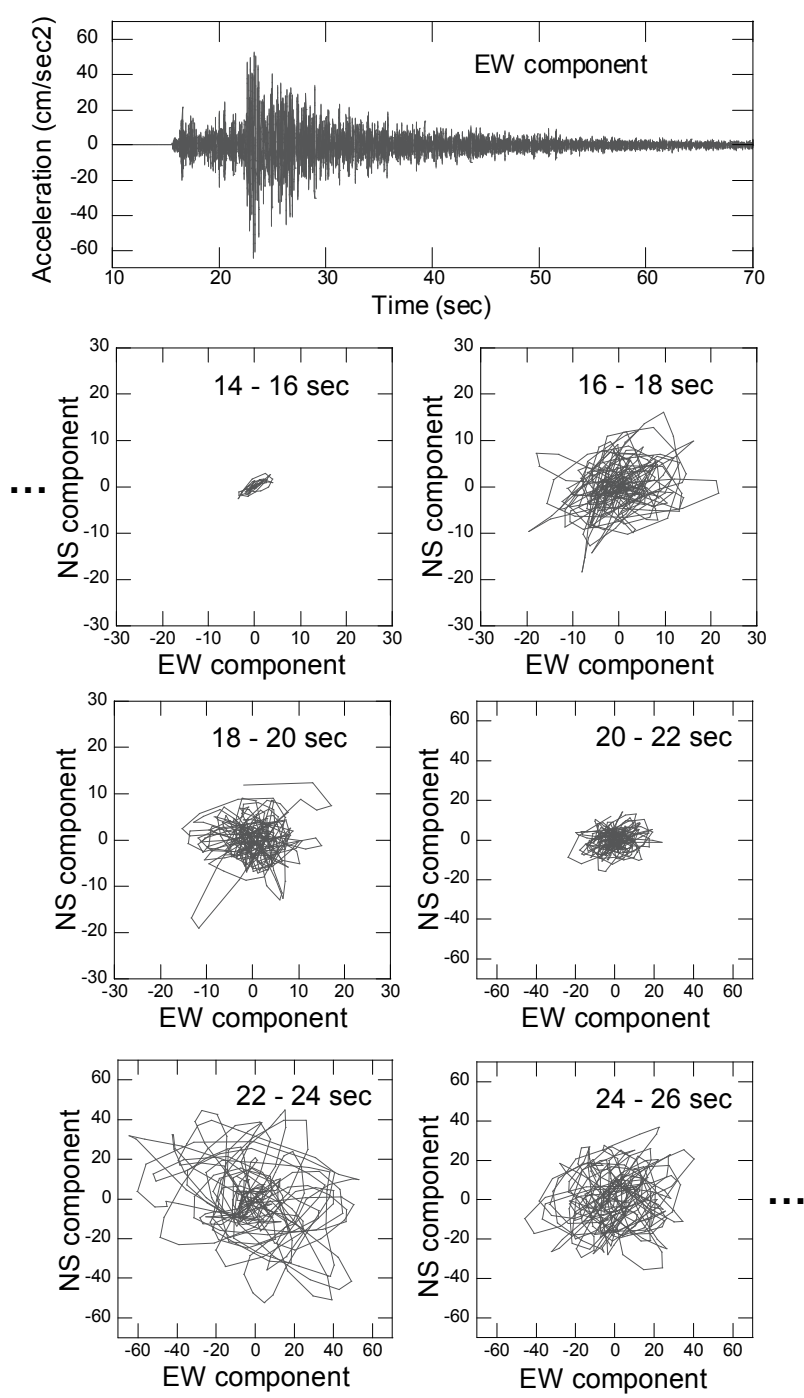

Fig. 5. Particle motion plots for two components of motion (CSM station, seismic event 2008/03/29 12:51).

amplification factor at the $j^{\text {th }}$ station, $R_{i j}$ the source distance between the $i^{\text {th }}$ event and the $j^{\text {th }}$ station, $Q_{S}(f)$ the average $Q_{S}$-value along the wave propagation path, and 

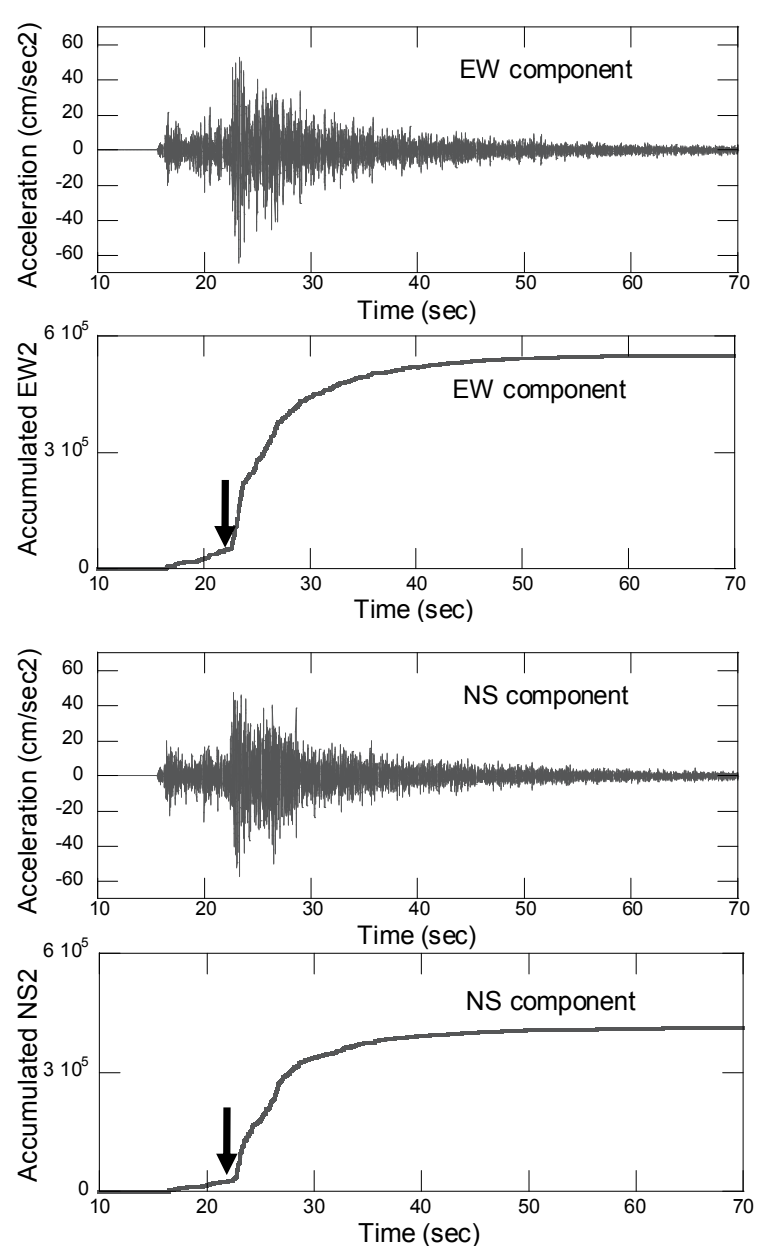

Fig. 6. Husid plots for recognizing S-wave onset time. Black arrows indicate S-wave onset time (CSM station, seismic event 2008/03/29 12:51).

$V_{S}$ the average S-wave velocity along the wave propagation path. Note that $3.5 \mathrm{~km} / \mathrm{sec}$ is assumed in this study. Eq. (1) is modified into a linear form by taking its logarithm. Source spectra, $Q_{S}$-value, and the site amplification factor at each station are obtained in a least-squares sense by the linear inversion method. As a constraint condition, we assigned the CDLCIP site as the reference site, which is located on a shallow, dense to very dense, coarse gravel. We set the site amplification factor for CDLCIP to be the same as that of the theoretical 1-D amplification of an Swave for the $V_{S}$ model. The factor of site amplification is constrained from 2 to about 5 at frequencies from 0.5 to $20 \mathrm{~Hz}$ as shown in Fig. 4. This constraint condition represents the free surface amplification effect.

As mentioned above, the spectral inversion method utilizes direct S-waves, so we selected an S-wave portion of two horizontal components, NS and EW, beginning at initial shear-wave arrival. In order to recognize the onset time of an S-wave, particle motion plots for two components of horizontal motion (Fig. 5) and Husid plots [13], where the horizontal axis is the time and vertical axis is the accumulated horizontal component square for each horizontal component (Fig. 6), were used. The end moment of the $S$ wave was picked up by using cumulative a
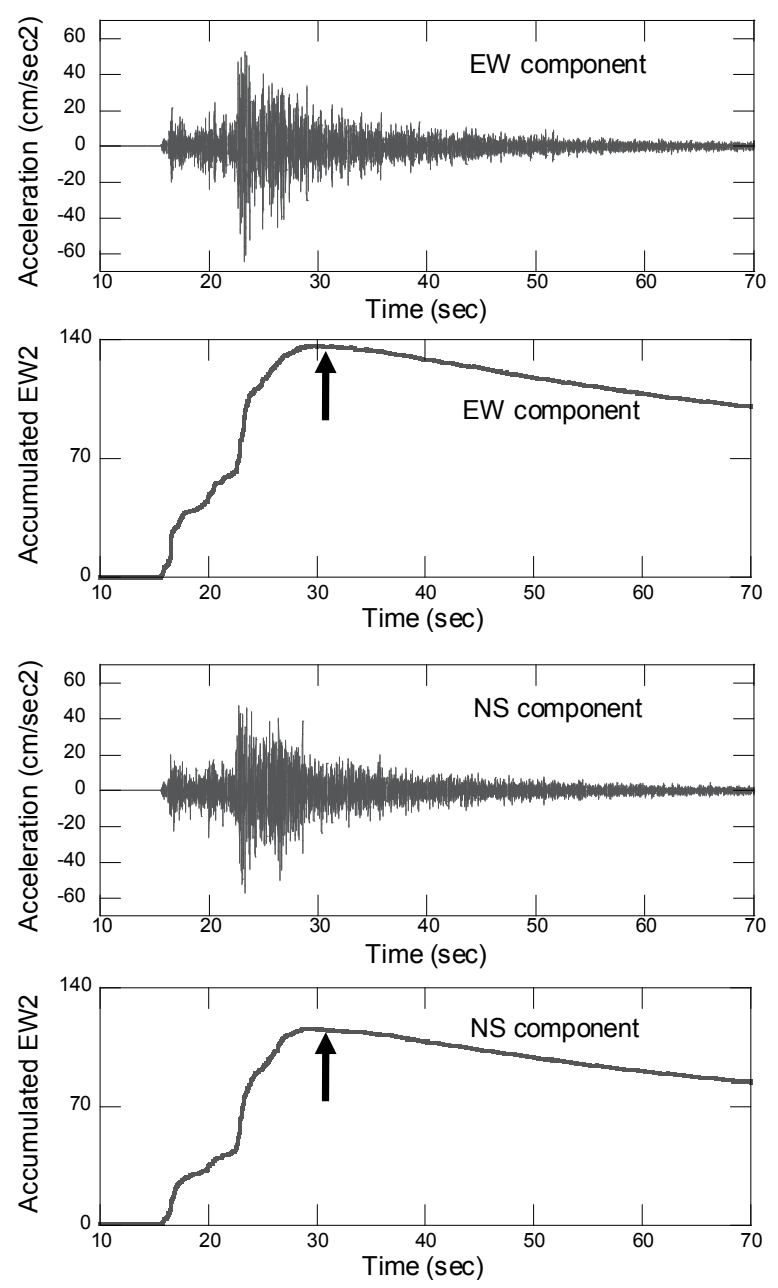

Fig. 7. Cumulative RMS plots for recognizing the $S$ wave end moment. Black arrows indicate S-wave end time (CSM station, seismic event 2008/03/29 12:51).

Root Mean Square (RMS) function [14]. In this study, the time at which the S-wave window ended was defined as the point on the time axis at which cumulative RMS starts to decrease, as illustrated in Fig. 7. The end moment of the $S$ wave was estimated visually.

After the onset and end times of the S-wave were determined, the S-wave portion was cosine-tapered 10 percent at each end of the time window, using the same criterion as that used by Takemura et al. (1990) [15], and Fouriertransformed into the spectrum. Spectral amplitudes were then smoothed with the 17-point moving average method. Fourier acceleration amplitude spectra of two horizontal components were computed and summed vectorially.

\section{Results}

\subsection{Source Spectra and $Q_{S}$-Value}

Source acceleration amplitude spectra were obtained from the inversion technique. It is divided over $\omega^{2}$ to obtain source displacement spectra and to replace in Eq. (2) 


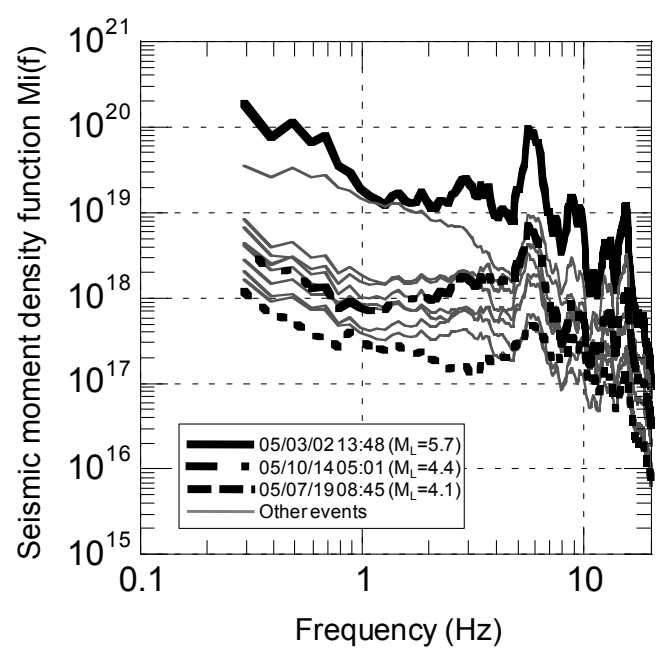

Fig. 8. Examples of seismic moment density functions.

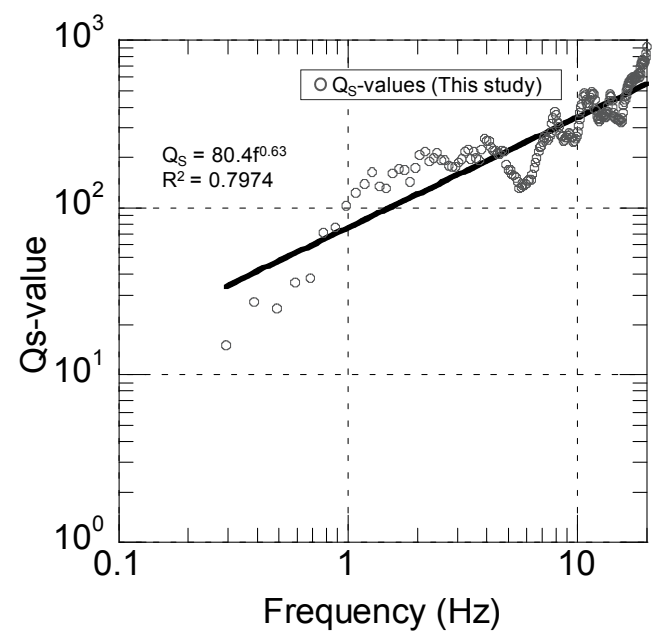

Fig. 9. $Q_{S}$-values as a function of frequency.

to get seismic moment density function $M(f)$.

$$
S_{i}(f)=R_{\theta \emptyset} M(f) / 4 \pi \rho v_{S}^{3}
$$

where $R_{\theta \emptyset}$, is the radiation pattern coefficient, $\rho$ density, and $v_{S} \mathrm{~S}$-wave velocity in the source layer [16]. A shearwave velocity of $4.0 \mathrm{~km} / \mathrm{s}$, density of $3.0 \mathrm{~g} / \mathrm{cm}^{3}$, and average point-source radiation pattern coefficient of 0.6 are assumed in this study. These coefficients were also assumed by Takemura et al. (1990) [15] and Kato et al. (1992) [17]. Fig. 8 shows source spectra for seismic events with $M_{L}$ from 4.0 to 5.7. Using thick curves, the amplification level of the seismic moment is seen to depend significantly on magnitude. A predominant peak at about $6 \mathrm{~Hz}$ is commonly found in source spectra, indicating difficulty in inversion at this frequency, as is explained later.

Figure 9 shows the $Q_{S}$-value obtained by inversion as a function of frequency. Formula $Q_{S}=80.4 f^{0.63}$ fits our results. A conspicuous trough is observed from this figure in the frequency range between 5 and $6 \mathrm{~Hz}$. Inversion results related to the $Q_{S}$-value are not stable in this frequency range due to a lack of sufficient data with a more uniform distribution for the hypocentral distance, as
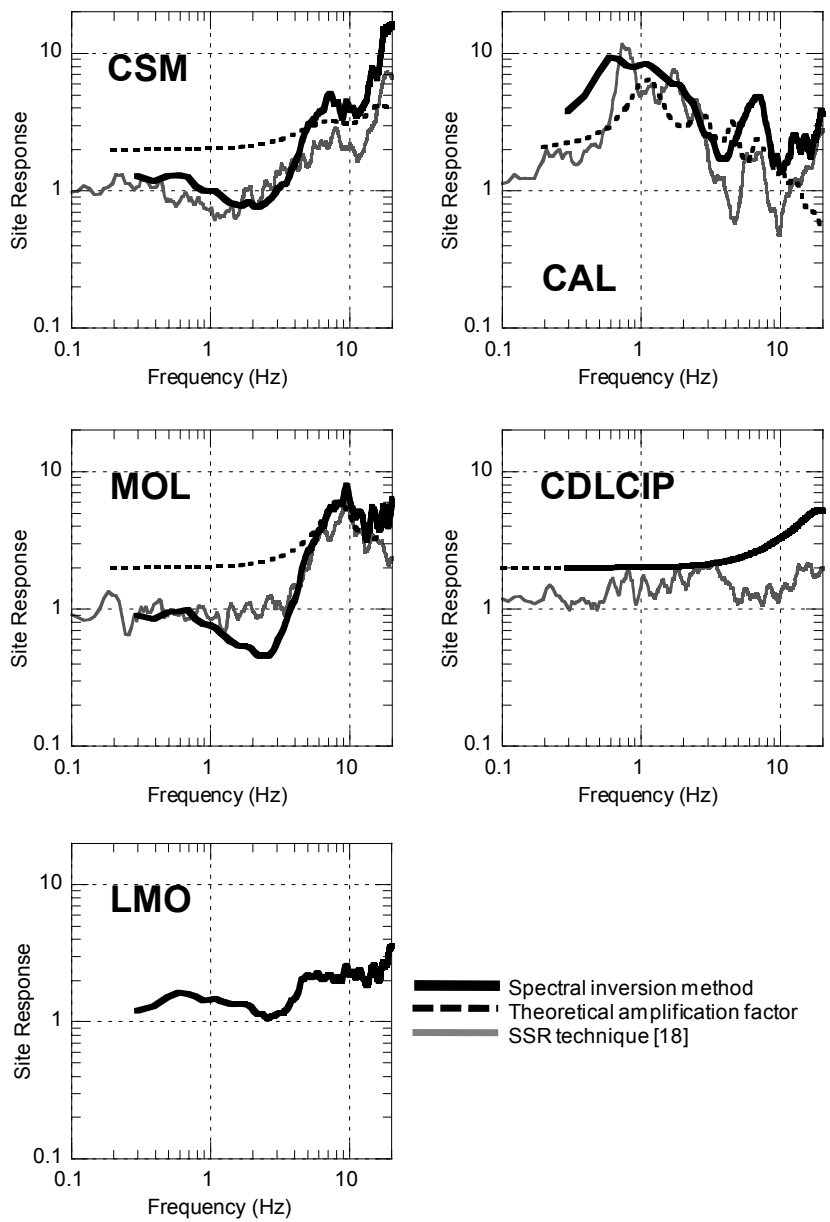

Spectral inversion method - - ' Theoretical am plification factor SSR technique [18]

Fig. 10. Comparison of site response for different techniques.

shown in Fig. 2. Having an inadequate hypocentral distance range in consideration of the propagation paths of direct $\mathrm{S}$-waves from source to station causes instability in the solution.

The significant trough observed in Fig. 9 also affects the form of the source spectrum, since a prominent peak in the same frequency range is also observed in spectra (Fig. 8). This is because the $Q_{S}$-value along the wave propagation path influences the source spectrum.

\subsection{Local Site Effects}

Figure 10 shows site amplification factors (thick solid lines) obtained by the spectral inversion method. Since S-wave velocity profiles of some stations are known, we calculated the theoretical 1-D transfer function of S-waves (broken lines) to compare results in Fig. 10.

There is agreement between the two results at high frequencies for CSM station. Broad peaks and troughs of the theoretical transfer function correspond to the site amplification factor obtained by inversion analysis. Narrow peaks and troughs of the theoretical transfer function for the CAL station are identified in the inversion result, but not all peaks and troughs of theoretical transfer functions are in agreement with results of the SIM because data of observed spectra used for evaluating the SIM are 
smoothed in frequency domain [17]. Consistency between the theoretical transfer function and the SIM is seen for MOL station only at high frequencies. Because the Swave velocity profile is not available in the case of the LMO station, it is not possible to calculate the theoretical transfer function. As described previously, this station is located on intrusive rock, so amplification levels at this site are less compared with other stations.

Our results indicate that there is good agreement at high frequencies between the two empirical methods. For frequencies lower than $5 \mathrm{~Hz}$, however, the site amplification factor - especially for the CSM, MOL and LMO sites - is under 2, even though free surface amplification has been considered for the inversion solution. One reason for this might be the reference site used in this study, which is a sediment site, not a rock site, which makes the solution in this frequency range unstable.

\section{Discussion}

\subsection{Comparison with the Site Amplification Factor and the Standard Spectral Ratio}

Cabrejos J. (2009) [18] estimated amplification of ground motion using records at the same stations as those evaluated in this study. In his study, he used the Standard Spectral Ratio (SSR). Since the spectral ratio is not necessary to know the $S$-wave velocity structure at the reference site, he used the LMO site, located on intrusive rock, as a reference site.

The site amplification factor obtained by the SIM is compared with the spectral ratio by Cabrejos $\mathrm{J}$. (2009) [18]. It is important to know that site amplification at all sites is defined as the ratio of surface motion to input motion from the bottom layer of the model for the reference site. The standard spectral ratio (SSR), in contrast, is defined as the ratio of surface motion at each site to surface motion at the reference site. The definition of site amplification in the SSR is different from that in the spectral inversion method because surface motion at the reference site is affected with the amplification of shallow soil due to weathering and the fractured nature of the rock near the surface [19]. The propagation path effect is also included in the standard spectral ratio but the SSR assumes that the path term will be cancelled when separation between stations is much less than their hypocentral distance from the source (as in Cabrejos' study). In spectral inversion, on the contrary, the three effects are automatically separated.

Figure 10 also displays a comparison between amplification from inversion (thick solid lines) and the SSR (thin lines). There is a similarity in the shape of the curves, peaks and troughs can be identified in both methods, both of which support our results - although different techniques for estimating the site response have been applied and different reference sites used, as previously mentioned. Nonetheless, absolute amplifications are systematically different from each other because of differences in their definitions.

\subsection{Surface Geology and Local Surface Conditions}

According to Fig. 1, CSM, CAL, MOL and CDLCIP sites are located on Quaternary alluvial deposits, with the exception of the LMO rock site. Fig. 10 shows that the CSM, MOL and CDLCIP stations show larger amplifications at frequencies above $4 \mathrm{~Hz}$. The CAL site, however, shows amplification levels much higher and predominant frequencies less than $4 \mathrm{~Hz}$, even though this station is also located on Quaternary deposits. According to the local surface conditions of these sites (Table 2), the CSM, MOL and CDLCIP sites are located over the Lima Conglomerate, which consists of a medium dense to very dense coarse gravel and sand with cobbles, extending from the ground surface to rock [5]. The CAL station, however, is located on gravel layers that overlie a thick clay deposit about $20 \mathrm{~m}$ thick. Finally, under this layer, there is a dense sandy gravel deposit [7].

Our results prove that stiff soil such as the Lima Conglomerate are likely to suffer from high amplification at frequencies larger than $4 \mathrm{~Hz}$, while places such as the Callao district, where the CAL site is located, show high amplification levels in a low-frequency range lower than $4 \mathrm{~Hz}$ because of unfavorable soil subsurface conditions.

\subsection{Microtremor Measurements}

Calderon et al. (2012) [20] made several microtremor measurements over Lima city in order to estimate soil profile characteristics. Two of these were carried out relatively close to the CAL and CSM stations. From their results, H/V spectra observed at the CAL site clearly show predominant peaks at $0.15 \mathrm{sec}$ and $0.5 \mathrm{sec}$ as well as at periods longer than $1.0 \mathrm{sec}$. These results are in good agreement with our spectral inversion results for this site (Fig. 10). For the CSM site, Calderon et al. (2012) [20] point out that a small bump has been identified at a period about $0.15 \mathrm{sec}$, which has also been detected in our results (Fig. 10).

\subsection{Average S-Wave Velocity and Site Amplifica- tion}

It is well known that the relationship between the site amplification factor and average shear wave velocity is a good indicator for estimating site effects $[21,22]$. Most studies propose trend lines that fit the relation between the two parameters. Because for this work, we do not count on enough data to propose reliable relationships, we only calculate the average site amplification in a frequency range from $0.5 \mathrm{~Hz}$ to $10.0 \mathrm{~Hz}$, as shown in Table 3. The average site amplification factor for this study is defined as the arithmetic average in the range of the analyzed frequency. We have taken into account the value of $V_{S 10}$ - average $S$-wave velocity in the top 10 meters of S-wave profiles - as a way to determine the relationship with the average amplification factor. This is because previous studies in the same area of interest [9] indicated that the average of the shear-wave velocity profile for the first 30 meters $\left(V_{S 30}\right)$ overestimate soil characteristics in 
Table 3. $V_{S 10}$ and the average site amplification factor.

\begin{tabular}{|ccc|}
\hline Site ID & $\begin{array}{c}\mathrm{V}_{\mathrm{S} 10} \\
(\mathrm{~m} / \mathrm{s})\end{array}$ & $\begin{array}{c}\text { Average Amplification Factor } \\
(0.5 \mathrm{~Hz}-10 \mathrm{~Hz})\end{array}$ \\
\hline CAL & 69.00 & 3.65 \\
MOL & 211.96 & 3.19 \\
CSM & 396.95 & 2.74 \\
CDLCIP & 397.49 & 2.48 \\
\hline
\end{tabular}

Table 4. Average transfer function $(A v T F)$.

\begin{tabular}{|ccc|}
\hline Site ID & Calculated AvTF & $\begin{array}{c}\text { AvTF proposed by Calderon D. (2012) [9], } \\
\text { according to the location of the sites }\end{array}$ \\
\hline CSM & 0.8 & $1.00-1.14$ \\
CAL & 2.7 & $>1.30$ \\
MOL & 0.7 & $1.00-1.14$ \\
CDLCIP & 1.1 & $1.00-1.14$ \\
LMO & 0.8 & $1.00-1.14$ \\
\hline
\end{tabular}

Lima. Table 3 shows value $V_{S 10}$ for the CAL, CSM, MOL and CDLCIP sites, as well as their respective average site amplification in the frequency range between $0.5 \mathrm{~Hz}$ and $10.0 \mathrm{~Hz}$. Note that there is a good correlation in this frequency range because stiff soils are likely to have low amplification. In the future, as part of this investigation, we intend to propose relationships between the two parameters by using new data belonging to other stations in Lima city to evaluate local site amplification.

\subsection{Amplification Map for Lima City}

Calderon D. (2012) [9] has proposed an amplification map for Lima city estimated from the Average Transfer Function $(A v T F)$ based on shallow S-wave profiles, since formerly this city does not count on one. $105 \mathrm{~S}$-wave velocity profiles obtained from the Multichannel Analysis of Surface Waves (MASW) are used to provide AvTF as well as to develop this map. Calderon used this adapted formula to calculate the average transfer function $(A v T F)$,

$$
A v T F=\frac{1}{0.95} \int_{0.05}^{1.0} T F(T) d T \text {. . . . . . }
$$

where $T F$ is the transfer function and $T$ the period. Note that this equation does not consider free surface amplification because ground response is expressed as the spectral ratio between motion to the surface and that at the reference site. The site response is likely to be near 1 at low frequency limits.

Since the site amplification factor obtained from the inversion result is now available for 5 stations, we calculated $A v T F$, using this equation for each site to look for agreement with the proposed soil amplification map. Note that because we considered free surface amplification in the inversion analysis, the site response is represented $2 E_{0} / E$, so we divided 2 of site amplification factor by the SIM.

Our calculations indicate that by using Eq. (3), the amplification factor for some of the sites is relatively low in comparison to the range of values that Calderon proposed on the amplification map, as shown in Table 4. Calculated
$A v T F$ for the CSM station is 0.8 , nonetheless, this site is expected to have $A v T F$ from 1.0 to 1.14 , according to the amplification map [9].

One of the reasons for this may be the reference site that we are using for this study, given that this reference site is located on alluvial gravel deposits and not at rock site, as we mentioned previously. Fig. 10 shows that the site amplification factor does not tend to be larger or equal than 2 at low frequencies in some sites, so the site response is not stable for this frequency range.

\section{Conclusions}

Using the spectral inversion method, site amplification factors at strong motion observation sites in Lima city have been evaluated from ground motion records observed during moderate seismic events. Most of the stations are located on alluvial soil deposits belonging to the Quaternary Holocene, but one station was installed on a rock site. Although the site response for sediment sites has large amplification at frequencies above $4 \mathrm{~Hz}$, one station - the CAL site - shows higher amplification levels at frequencies below $4 \mathrm{~Hz}$. This difference is because of local subsurface conditions - this station is located on soft soil, while others are on alluvial gravel deposits. At the rock site, the amplification level is less than that at other stations.

Obtained results were confirmed with the standard spectral ratio [18]. The same peaks and troughs are identified in the two techniques, even though the definition of absolute amplification differs between the two. The H/V spectra observed and obtained from microtremor measurement [20] also support the site response at our stations. The relationship between $V_{S 10}$ and the average site amplification factor show good correlation at a frequency range from $0.5 \mathrm{~Hz}$ to $10.0 \mathrm{~Hz}$. We also have compared our results with the amplification map for Lima city using an adapted formula [9]. Our calculations differ a little from this map probably because of the reference site that we are using in this study - a site that is located on gravel deposits and not on a rock site.

In terms of the $Q_{S}$-value obtained in this study, there is a conspicuous trough in the frequency range between 5 and $6 \mathrm{~Hz}$ because our data set does not count on uniform distribution for the hypocentral distance. It is therefore recommended that we reanalyze these results with new data to improve results.

\section{Acknowledgements}

The authors thank the Geophysical Institute of Peru (IGP) for supplying information on instrument location belonging to IGP, as well as for providing the accelerograms data recorded by this instrument. We are likewise grateful to the research assistants at CISMID who helped in the completion of this study.

This research was supported by the Japan International Cooperation Agency (JICA) in cooperation with National Graduate Institute for Policy Studies (GRIPS) and the International Institute of Seismology and Earthquake Engineering (IISEE). 


\section{References:}

[1] T. Iwata and K. Irikura, "Source parameters of the 1983 Japan Sea Earthquake sequence,” J. Phys. Earth., Vol.36, pp. 155-184, 1988.

[2] T. Iwata and K. Irikura, "Separation of source, propagation and site effects from observed S-waves," Zisin II (J. Seismol. Soc. Jpn.), Vol.39, pp. 579-593, 1986 (in Japanese with English Abstract).

[3] K. L. Lee and J. Monge, "Effect of soil conditions on damage in the Peru earthquake of October 17, 1966," Bull. Seism. Soc. Am., Vol.58, pp. 937-962, 1968.

[4] C. Lomnitz and R. Cabré, "The Peru earthquake of October 17, 1966,” Bull. Seism. Soc. Am., Vol.58, pp. 645-661, 1968.

[5] P. Repetto, I. Arango, and H. B. Seed, "Influence of site characteristics on building damage during the October 3, 1974 Lima earthquake," Report-Earthquake Engineering Research Center, College of Engineering, University of California, Berkeley, California, NTIS, pp. 80-41, 1980.

[6] J. P. Le Roux, C. Tavares, and F. Alayza, "Sedimentology of the Rimac-Chillon alluvial fan at Lima, Peru, as related to PlioPleistocene sea-level changes, glacial cycles and tectonics," Journal of South American Earth Sciences, Vol.13, pp. 499-510, 2002.

[7] Z. Aguilar, "Seismic Microzonation of Lima," Japan-Peru Workshop on Earthquake Disaster Mitigation, Japan-Peru Center for Earthquake Engineering and Disaster Mitigation (CISMID), Faculty of Civil Engineering, National University of Engineering, Lima, Peru, 2005.

[8] W. R. Stephenson, R. A. Benites, and P. N. Davenport, "Localized coherent response of the La Molina basin (Lima, Peru) to earthquakes, and future approaches suggested by Parkway basin (New Zealand) experience," Solid dynamics and earthquake engineering, Vol.29, No.10, pp. 1347-1357, 2009.

[9] D. Calderon, "Dynamic characteristics of the soils in Lima, Peru, by estimating shallow and deep shear-wave velocity profiles," Graduate School of Engineering, Chiba University, Japan, 2012.

[10] A. Martínez and F. Porturas, "Planos Geotécnicos para Lima, Perú", Análisis y Visión en Ingeniería Sísmica, Pontificia Universidad Católica del Perú, Lima, Perú, 1975 (in Spanish).

[11] I. Bernal and H. Tavera, "Aceleraciones máximas registradas en la ciudad de Lima: Sismo de Pisco del 15 de Agosto del 2007 (7.0 $\mathrm{M}_{\mathrm{L}}$ )," Informe preliminar, 2007 (in Spanish).

[12] J. Riepl, P.-Y. Bard, D. Hatzheld, C. Papaionnou, and S. Nechtschein, "Detail evaluation of site response estimation methods across and along the sedimentary valley of Volvi (EUROSEISTEST)," Bull. Seism. Soc. Am., Vol.88, pp. 488-502, 1998.

[13] L. R. Husid, "Características de terremotos - análisis general," Revista del IDIEM 8, pp. 21-42, Santiago, Chile, 1969 (in Spanish).

[14] M. W. J. McCann and H. C. Shah, "Determining strong motion duration of earthquakes,” Bull. Seismol. Soc. Am., Vol.69, pp. 1253$1265,1979$.

[15] M. Takemura, T. Ikeura, and R. Sato, "Scaling relations for source parameters and magnitude of Earthquake in the Izu Peninsula Region,” Tohoku Geophys. J. (Sci. Rep. Tohoku Univ., Ser. 5), Vol.32, pp. 77-89, 1990.

[16] H. Kanamori, "Mechanism of tsunami earthquakes," Phys. Earth Planet. Inter., Vol.6, pp. 346-359, 1972.

[17] K. Kato, M. Takemura, T. Ikeura, K. Urao, and T. Uetake, "Preliminary analysis for evaluation of local site effect from strong motion spectra by an Inversion Method," J. Pyhs. Earth, Vol.40, pp. 175191, 1992.

[18] J. Cabrejos, "Amplificación sísmica en la ciudad de Lima aplicando la Técnica de Cocientes Espectrales," Facultad de Ingeniería Civil, Universidad Nacional de Ingeniería, Lima, Peru, 2009 (in Spanish).

[19] J. H. Steidl, A. G. Tumarkin, and R. J. Archuleta, "What is a reference site?," Bull. Seism. Soc. Am., Vol.86, pp. 1733-1748, 1996.

[20] D. Calderon, T. Sekiguchi, S. Nakai, Z. Aguilar, and F. Lazares, "Study of soil amplification dased on microtremor and seismic records in Lima Peru," Journal of Japan Association for Earthquake Engineering, Vol.12, No.2, 2012.

[21] R. D. Borcherdt, "Estimates of site-dependent response spectra for design (methodology and justification)," Earthquake Spectra, Vol.10, pp. 617-653, 1994

[22] D. M. Boore, "Estimating $V_{S} 30$ (or NEHRP site classes) from shallow velocity models (depths $<30 \mathrm{~m}$ ), "Bulletin of the Seismological Society of America, Vol.94, pp. 591-597, 2004.

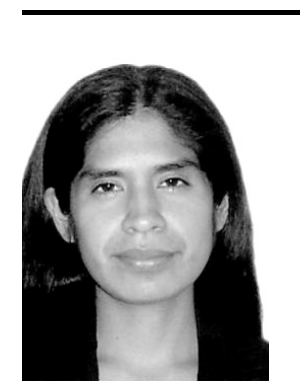

Name:

Selene Quispe

\section{Affiliation:}

Ph.D. Candidate, Department of Environmental Science and Technology, Tokyo Institute of Technology

Address:

4259 Nagatsuta, Midori-ku, Yokohama, Kanagawa 226-8502, Japan Brief Career:

2007 State Engineer, National University of Engineering, Peru 2010 State Engineer, National Graduate Institute for Policy Studies, Japan 2012 Student in Doctoral Course, Tokyo Institute of Technology Selected Publications:

- "Evaluation of Local Site Effects in Lima City, Peru from Ground Motion Data," Proceeding of the $15^{\text {th }}$ World Conference on Earthquake Engineering - Lisbon, Paper 1184, 2012.

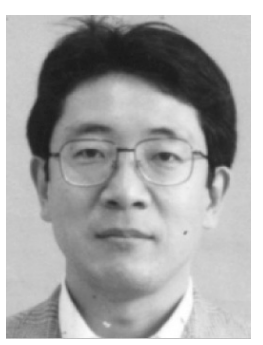

Name:

Hiroaki Yamanaka

\section{Affiliation:}

Professor, Department of Environmental Science and Technology, Tokyo Institute of Technology

Address:

4259 Nagatsuta, Midori-ku, Yokohama, Kanagawa 226-8502, Japan

Brief Career:

1989 Research Fellow, Tokyo Institute of Technology

1990 Research Associate, University of Southern California

1991 Research Engineer, Kajima Corporation

1995 Associate Professor, Tokyo Institute of Technology

2012 Professor, Tokyo Institute of Technology

Selected Publications:

- "Estimation of site amplification and S-wave velocity profiles in metropolitan Manila, the Philippines, from earthquake ground motion records," Exploration Geophysics, Vol.42, No.1, pp. 69-79, 2011.

Academic Societies \& Scientific Organizations:

- Society of Exploration Geophysicists of Japan

- Seismological Society of Japan

- Japan Association of Earthquake Engineering

- Architectural Institute of Japan 


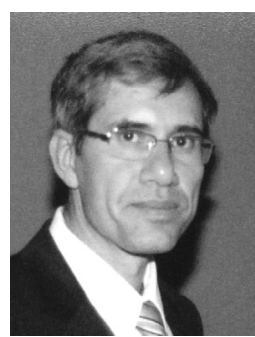

Name:

Zenon Aguilar

\section{Affiliation:}

Professor, Faculty of Civil Engineering, National University of Engineering

Address:

Av. Túpac Amaru $\mathrm{N}^{\circ}$ 1150, Lima 25, Peru

Brief Career:

1999 Doctoral Student, Kyoto University

2012 Professor, National University of Engineering, Peru

2012 Manager, ZER Geosystem PERU SAC

\section{Selected Publications:}

- "Seismic Microzonation of Lima," Japan-Peru Workshop on Earthquake Disaster Mitigation, Japan-Peru Center for Earthquake Engineering and

Disaster Mitigation (CISMID), 2005.

Academic Societies \& Scientific Organizations:

- American Society of Civil Engineers (ASCE)

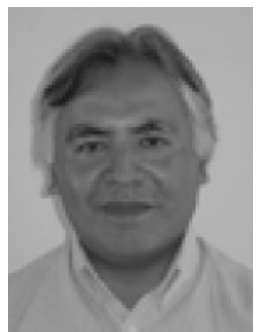

\section{Name:}

Fernando Lazares

\section{Affiliation:}

Professor, Faculty of Civil Engineering, National University of Engineering

\section{Address:}

Av. Túpac Amaru $N^{\circ}$ 1150, Lima 25, Peru

Brief Career:

2003 Master Student, National Autonomous University of Mexico

2012 Professor, National University of Engineering, Peru

\section{Selected Publications:}

- "CISMID Accelerometer Network," Japan-Peru Workshop on

Earthquake Disaster Mitigation, Japan-Peru Center for Earthquake

Engineering and Disaster Mitigation (CISMID), 2005.

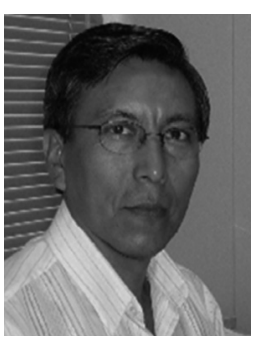

\section{Name:}

Hernando Tavera

\section{Affiliation:}

Director, Department of Seismology, Geophysical Institute of Peru

\section{Address:}

Calle Badajoz \# 169 - Mayorazgo IV Etapa - Ate Vitarte, Lima, Peru Brief Career:

2012 Director, Department of Seismology, Geophysical Institute of Peru 2012 Scientific Researcher, Geophysical Institute of Peru

\section{Selected Publications:}

- H. Tavera, "A Report on the 24 August $2011 \mathrm{Mw} 7.0$ Contamana, Peru, Intermediate-Depth Earthquake," Seismological Research Letters, Vol.83, No.4, doi: 10.1785/0220120005, 2012.

- K. Phillips, R. W. Clayton, P. Davis, H. Tavera, R. Guy, S. Skinner, I. Stubailo, L. Audin, and V. Aguilar, "Structure of the subduction system in southern Peru from seismic array data," J. Geophys. Res., Vol.117, B11306, doi:10.1029/2012JB009540, 2012.

- M. Chlieh, H. Perfettini, H. Tavera, J.-P. Avouac, D. Remy, J.-M. Nocquet, F. Rolandone, F. Bondoux, G. Gabalda, and S. Bonvalot, "Interseismic coupling and seismic potential along the Central Andes subduction zone," J. Geophys. Res., Vol.116, B12405, doi:10.1029/2010JB008166, 2011.

- H. Tavera, I. Bernal, F. Strasser, M. Arango-gavina, J. Alarcon, and J. Bommer, "Ground motions observed during the 15 August 2007 Pisco, Peru, earthquake," Bulletin of Earthquake Engineering, doi:10.1007/s10518-008-9083-4, 2008.

Academic Societies \& Scientific Organizations:

- IASPEI, Seismology section (LASC)

-Sociedad Geologica del Peru 